\title{
AN INVESTIGATION INTO THE EFFECTS OF GLUTAMIC ACID ON HUMAN INTELLIGENCE
}

\author{
BY \\ J. R. MILLIKEN and J. L. STANDEN \\ From the Institute of Psychiatry, the Maudsley Hospital, London
}

Since 1943 there have been many reports of investigations conducted to determine whether the oral administration of supranormal quantities of glutamic acid is followed by an improvement in cognitive and other functions. Both rats and human beings have been used as subjects, and the literature shows that both positive and negative results have been obtained. Working with rats, Albert and Warden (1944) and Zimmerman and Ross (1944) have reported improvements in performance in problems of the maze type, but point out that no significant changes in weight or growth were observed. Hamilton and Maher (1947) reported that the experimental animals " showed a significantly higher activity level than the controls" on the three-table test of " reasoning", but that they observed no significant differences in actual test scores on this test or on tests of timidity which were administered after the three-table test. Entirely negative results were obtained by Stellar and McElroy (1948) and Marx (1948) from measures of test performance and of weight, and the latter also observed no increases in the activity level. With human beings as subjects, Price, Waelsch, and Putnam (1943) and Waelsch and Price (1944) have reported that patients suffering from petit mal improved in behaviour and in the frequency and severity of their seizures. With mentally retarded subjects, improvement in performance on cognitive tests has been reported by Gasorek (1948), Zimmerman, Burgemeister, and Putnam (1948), and Albert, Hoch, and Waelsch (1946). The last named reported improvement on personality tests also. Zimmerman, Burgemeister, and Putnam (1949a, and b) reported improvements in mongoloid patients on verbal tests, and in behaviour and general physical condition. The same investigators $(1946,1947)$ found in mentally retarded patients suffering from convulsive disorders that they improved in performance on psychological tests of personality and of cognitive functions, as $\mathrm{w}^{\prime}$ in activity level and behaviour. Schizophrenı ab- jects were used by Ewalt and Bruce (1948) and Kitzinger, DeVere, Cartwright, and Shapiro (1949), who reported improvements in personality (as estimated by tests), activity level, and behaviour. Harney (1950) found that glutamic acid had a beneficial effect upon the mental age, personality, and school achievement of retarded girls.

The present experiment was designed to test the hypothesis that the oral administration of glutamic acid to human subjects would be followed by improvements in their scores on psychological tests of intelligence, both of the verbal and the performance type. In view of the reports of improvement in personality and behaviour, the body sway test was also included, on account of its brevity, simplicity, and its correlation with neuroticism (Eysenck, 1947). To this was subsequently added the static ataxia test, which has the same advantages (Eysenck, 1947). The additional hypothesis was that the administration of glutamic acid would be followed by a decrease in the scores on these tests of neuroticism.

The administration of the experiment, including the selection and matching of the subjects, was the responsibility of the psychiatrist (J. R. Milliken). The actual testing, and the analysis of the results after the completion of the testing, were carried out by the psychologist (J. L. Standen), who was unaware which subjects were experimental and which control until the testing was finished.

\section{Plan of the Experiment}

Three main groups of subjects were chosen : (1) adult patients in a mental defectives' institution; (2) child patients in the same institution ; (3) boys of a normal range of intelligence, living in a home.

The last-named group was subdivided into " seniors" and " juniors", the seniors being all those over the age of 10 , and those under 10 who were able to complete the Thurstone primary mental abilities test which was taken by all the boys over 10 . The remainder of the boys constituted the junior group.

It was found possible at a later stage of the experiment 
to add another group of adult defectives, so that the experiment was actually conducted with five distinct groups of subjects. For convenience of reference, they were described as " Adult Defectives Group I ", " Adult Defectives Group II ", " Defective Children ", " Senior Normals", and " Junior Normals".

Each of these groups was divided, after the initial testing, into an experimental section (" $E$ ") and a control section (" $C$ "). In every case, the members of the $\mathrm{E}$ section received glutamic acid, and the members of the $\mathbf{C}$ section received a control mixture during the same period. At the end of the period (four months in the case of the three defective groups, and three in the case of the normals) every subject was again tested, with the same or equivalent tests as on the first occasion. The roles of the two sections within each group were then reversed, so that subjects who were formerly experimental became controls, and vice versa, for a second period of treatment of the same duration as the first, at the end of which the test battery was administered for the third time.

At the beginning of the experiment each subject in the $\mathrm{E}$ section was matched as closely as possible, on the basis of age, sex, and intelligence, with a subject in the corresponding $\mathbf{C}$ section.

\section{Selection of the Subjects}

Adult Mental Defectives, Group I.-A preliminary selection was made of 88 adult patients in the Manor Hospital, Epsom, who would be in the 21-29 age group when the experiment began. From this number there were then rejected $(a)$ those with a history of epilepsy or organic nervous disease ; (b) those who showed any signs of organic nervous disease on physical examination; (c) those who were in isolated wards of the hospital in numbers insufficient to justify the special supervision necessary ; $(d)$ those whose I.Q.s were below 45 on the new Stanford-Binet scale.

There were 36 remaining, of whom only 26 continued to receive glutamic acid or the placebo regularly for four months, and 23 then completed the second period of four months. The I.Q. range of the 26 was $48-72$. Those who failed to complete the experiment did so for reasons beyond the experimenters' control.

Defective Children.-All children in the hospital whose ages were between 10 and 14 years were first selected, and from these were rejected those who fell into categories $(a),(b)$, and $(d)$ as defined above. There remained 20 , of whom 16 completed both the four month periods. Their I.Q. range was 41-66.

Normal Boys.-All the boys in Dr. Barnardo's Home, New Lodge, Windsor, whose ages were between six and 15 were first chosen, and from these were rejected those who fell into categories $(a)$ and (b), and also those who were likely to leave the home before the end of the experiment. Of the number remaining, all those over 10 were tested with the Thurstone primary mental abilities group test. Those between eight and 10 were given the same test, and the ten boys who were most successful, as measured by the sum of the scores on the wordmeaning and the reasoning tests, were included in the senior group. The remainder constituted the junior group. Sixty-one members of the senior group completed the first period of three months, and 56 completed the second period. In the junior group, 24 completed the first period, and 21 the second period. The members of the senior group were tested with the Wechsler-Bellevue intelligence scale I, and their I.Q.s ranged from 65 to 112, with the exception of two boys, whose I.Q.s were 58 . The I.Q. range of the juniors, who were tested with the new Stanford-Binet scale, was 67-112.

Adult Mental Defectives, Group II.-This group was added when the second stage of treatment had been reached by Group I. It consisted entirely of women, who were selected according to the same criteria as Group I, except that the lower I.Q. limit was set at 40 . Twelve patients became available, with I.Q.s ranging from 43 to 74 . They received only one period of treatment (four months).

The subjects in each group were paired on the basis of age, sex, and intelligence (i.e. the Binet I.Q. in all cases except the senior boys, whose intelligence was measured, for this purpose, by the sum of the scores made on the word-meaning and the reasoning sections of the P.M.A.), and the result of a coin-toss determined which member of each pair was allocated? to the E section of the group.

\section{Materials and Administration}

The 1-glutamic acid solution (sodium glutamate) was made up by mixing 1-glutamic acid in distilled water and neutralizing with caustic soda solution to $p \mathrm{H} \mathrm{7,} \mathrm{the}$ strength of the final solution being such that $1 \mathrm{~g}$. glutamic acid was contained in $4 \mathrm{ml}$. Sacch. ust. was added to approximate the colour to that of the control solution. The control solution was made up of yeast extract 2, sodium chloride 3, aq. chlor. 25, water to 100 .

Both these solutions had a similar appearance and taste. They were either made up freshly each week or stored in a refrigerator up to a maximum of three weeks. As a check on the 1-glutamic acid content of the solution used, two specimens were determined by 1-glutamic acid decarboxylase. Both were initially described as containing $25 \mathrm{~g}$. glutamic acid per $100 \mathrm{ml}$. The first, tested after five months, during nearly the whole of which time it had been kept in a refrigerator, contained $20.1 \mathrm{~g} . / 100$ ml. The second, tested after three weeks kept mostly at room temperature, contained $19.9 \mathrm{~g} . / 100 \mathrm{ml}$.

The solutions were administered by mouth in water twice or three times a day, with or before a meal. In all cases the beginning dose of glutamic acid was $12 \mathrm{~g}$. per 
day, and this was increased to a maximum of 20-36 $\mathrm{g}$. per day in different subjects. Those in the control groups received corresponding amounts of the control solution.

In all cases the period of administration of each solution was not less than 12 weeks in the two normal groups, and 15-16 weeks in the three defective groups. After stopping the administration of either solution to any subject, the intelligence and other tests were administered after an interval of not less than six hours nor more than two days ; within a week of the discontinuance, the administration of the other solution was begun.

The 1-glutamic acid and control solutions were labelled " Mixture $Z$ " and " Mixture A ", and neither the staff nor the subjects were aware which mixture contained glutamic acid.

\section{Clinical Progress}

Before the treatment began the subjects were interviewed, examined physically, and told that they were to be given a special kind of tonic, which, it was hoped, would make them quicker, and that they would be tested before and after to find out if they had benefited. With a few exceptions they seemed anxious to cooperate, and in only five cases was it necessary to discontinue the treatment because of the subject's refusal to take the tonic.

The noticeable effects of the administration were few. In two adults vomiting occurred on several occasions after glutamic acid, but not after the control mixture. Many complaints of a feeling of nausea, particularly in the morning, were reported. Among the children, 28 complained of feeling sick after the glutamic acid, and four after both solutions. Six children vomited on several occasions after glutamic acid.

No other effect was noted throughout the whole period of the experiment, except that the Superintendent of the boys' home noted that two of the boys, generally difficult to manage and subject to violent outbursts of temper, had ceased to have any outbursts of temper while they were receiving Mixture $\mathrm{Z}$ (glutamic acid), but that within one week of starting to have Mixture $A$, their former behaviour had reasserted itself. One of the boys was then put on Mixture $A$ and the other on Mixture Z. During the following week the boy on the control mixture had several temper outbursts, while the other had none. At the beginning of the next week the mixtures were exchanged, and during this week neither of the boys was reported to be difficult. Eight months after the cessation of the treatment, the Superintendent reported that both boys had reverted to their former behaviour; arrangements are being made for them to resume the treatment. The I.Q. (Wechsler) of one of the boys, aged 14 years 3 months at the beginning of the experiment, was 58 . It had increased to 68 after three months on the control mixture, and to 73 after three months on glutamic acid. The corresponding I.Q.s of the other boy, aged 10 years 5 months were 78,83 , and 86 . Increases of this order were frequent in both the $\mathrm{E}$ and $\mathrm{C}$ sections of the group (senior normal).

In view of the few side-effects noted, it was decided to give rapidly increasing doses of glutamic acid to a small group of subjects in whom no effects had previously been noticed. Four women in the 21-29 age group and four defective boys in the 10-14 age group were selected, and were given a sludge of glutamic acid powder in water, starting with $24 \mathrm{~g}$. per day in divided doses and increasing by $12 \mathrm{~g}$. per day. On the first and second days, due to a misunderstanding, the four boys each received 72 and $108 \mathrm{~g}$., without showing any consequences save a slight feeling of nausea. After reverting to the planned dosage, they and the four adult subjects continued to have increasing doses until each was having $96 \mathrm{~g}$. of glutamic acid per day. After one week no effects had been noticed in the adults, but two of the children were more active and excitable.

\section{The Tests}

For the defective adults Group I, the defective children, and the normal boys junior group, the following battery, known as " $\mathrm{T}_{1}$ ", was used at the beginning of the experiment, before any medication had been started.

Revised Stanford-Binet, Form L

Kohs' blocks (Drever-Collins version)

Manikin and profile object assembly test (DreverCollins)

Healy picture completion test No. 1 (DreverCollins)

Goodenough " drawing a man" test

Body sway test of suggestibility

The batteries used for the second and third testing sessions (" $\mathrm{T}_{2}$ " and " $\mathrm{T}_{3}$ " respectively) were the same as the above, except that the static ataxia test was introduced immediately before the body sway test, and that the Binet form $M$ was used in place of form $L$ in $T_{2}$. In $T_{3}$, form $L$ was used again.

The defective adults Group II, who were, as previously indicated, added when the other defective groups were entering the second phase of the experiment, were given the same battery that has already been described. In their $T_{1}$, the Binet form $M$ was used, and form $L$ in their $T_{2}$. The static ataxia test was included on both occasions.

The battery used for the normal boys senior group was as follows :

Wechsler-Bellevue intelligence scale I

Goodenough "drawing a man " test

Static ataxia test (in $T_{2}$ and $T_{8}$ ) 
Body sway test

Thurstone primary mental abilities group test

Rorschach group test (using lantern-slides of the ink-blots)

Maudsley letter series group test

After the rejection of those subjects who failed to satisfy the criteria previously stated, a few more were lost from each group, either because they could not be matched sufficiently closely, or because of refusal to take the mixture, or because of unexpectedly becoming unavailable within a few days of the completion of $T_{1}$. All who were rejected for any of these reasons were classified as " not used", and their mean I.Q.s have been compared with the mean I.Q.s of those who were used. Table I shows the results of these comparisons.

In the case of the defective children, where a highly significant difference occurs, the reason for the rejection of all three subjects was inability to match.

At later stages in the experiment a few more subjects were lost for reasons beyond the control of the experimenters, and it also happened occasionally that a subject was not able to take all the tests in the battery. Due to the disturbance of the matching thus entailed, a modification was introduced into the statistical treatment of the data.

\section{The Statistical Technique}

The hypothesis to be tested was that the mean improvement of the experimental section on any test would be significantly greater than the corresponding improvement of the control section.

If $\mathrm{G}$ represents the effect attributable to glutamic acid, and $P$ the effect attributable to the placebo, it is possible to derive from the test scores obtained in this type of experiment an estimate of the difference G-P, representing the excess of the improvement due to glutamic acid over that due to the placebo, and to test the significance of this estimate. Since the sign of this difference is specified by the hypothesis (positive in all cases except that of the static ataxia and body sway tests, where the sign is negative), the significance of the estimated difference can be tested by the one-tail t-test when the difference is in the predicted direction. Those differences which are not found to be in the predicted direction show immediately without testing that the hypothesis is not confirmed.

The procedure adopted was as follows. From the score of each subject on a test in $T_{2}$ was deducted his score on that test in $T_{1}$. The resulting difference, $D$, with its sign, represented the subject's improvement (or otherwise) during the first period of the experiment. If the mean improvement of the experimental subjects is written $\overline{\mathbf{D}}_{\mathrm{c}}$, and the mean improvement of the controls is written $\overline{\mathbf{D}}_{c}$, then the expression $\overline{\mathbf{D}}_{\mathrm{e}}-\overline{\mathbf{D}}_{\mathrm{c}}$ represents that function of the test scores which was taken as the estimate of G-P. The effects of growth, practice and errors were assumed to be equal, on the average, between the experimental and control sections of the group tested.

The same procedure was adopted in the treatment of the scores made on the tests in $T_{2}$ and $T_{3}$, which were administered at the beginning and end respectively of the second period of the experiment. In this case, $D^{1}$ represents the score on a test in $T_{3}$ minus the score on the same test in $T_{2}$, and it can be shown algebraically that the function $\overline{\mathbf{D}}^{1} \mathrm{e}^{-}-\overline{\mathbf{D}}^{1} \mathrm{c}$ is an estimate of twice the difference G-P, on the same assumption that the effects of growth, practice, and errors cancel out.

The technique of analysis of variance, of which the ordinary t-test is the simplest case, was used for the treatment of the data. It was originally intended to use that version of the technique which has been devised for data obtained from matched groups, such as were arranged for this experiment, but owing to the loss of some of the subjects after the matching had been carried out, and to the already small numbers of subjects in the groups, it was decided, in consultation with A. Lubin, to disregard the matching entirely, and to apply the analysis of variance technique in its ordinary form. There was no reason to suppose that this introduced any bias. Fisher states (1941) that

" In cases in which each observation of one series corresponds in some respects to a particular observation of the second series, it is always legitimate to take the differences and test them .... as a single sample; but it is not always desirable to do so. A more precise comparison is obtainable by this method only if the corresponding values of the two series are positively correlated, and only if they are correlated

TABLE I

\begin{tabular}{|c|c|c|c|c|c|c|c|c|}
\hline \multirow{2}{*}{ Group } & \multirow{2}{*}{ Test } & \multicolumn{2}{|c|}{ Numbers } & \multicolumn{2}{|c|}{ Mean I.Q.s } & \multicolumn{2}{|c|}{ Variances } & \multirow{2}{*}{$\begin{array}{l}\text { Significance } \\
\text { of Difference }\end{array}$} \\
\hline & & Used & Not Used & Used & Not Used & Used & Not Used & \\
\hline Defective adults I & Binet & 26 & 9 & $58 \cdot 4$ & $65 \cdot 0$ & $72 \cdot 2$ & $152 \cdot 0$ & - \\
\hline Defective adults II $\ldots$ & Binet & 12 & 2 & $57 \cdot 8$ & $61 \cdot 5$ & $163 \cdot 4$ & $0 \cdot 5$ & - \\
\hline Defective children $\ldots$ & Binet & 16 & 3 & $49 \cdot 2$ & $61 \cdot 7$ & $51 \cdot 8$ & $369 \cdot 3$ & $\cdot 1 \%$ \\
\hline Senior normal boys .. & Wechsler & 61 & 16 & $88 \cdot 1$ & $86 \cdot 3$ & $147 \cdot 7$ & $169 \cdot 2$ & - \\
\hline Junior normal boys . . & Binet & 24 & 4 & $95 \cdot 0$ & $80 \cdot 0$ & $142 \cdot 1$ & $86 \cdot 0$ & $2.5 \%$ \\
\hline
\end{tabular}


to a sufficient extent to counterbalance the loss of precision due to basing our estimate of variance upon fewer degrees of freedom.'

In the present case, using the method for matched groups (i.e. the first method described by Fisher) would have entailed the loss of unmatched subjects as well as half the total number of matched subjects in each group, for the purpose of computing the number of degrees of freedom available. It should be noted that the two "series of observations" which were compared were not the actual scores on the tests, but the differences between the scores on successive administration of the tests.

\section{The Results}

Table II shows the results obtained from the test scores made by members of four of the groups, and the results from the fifth group are shown in Table III. The "drawing a man" test, and the group Rorschach and Maudsley letter series have not yet been scored, and their results will form the subject of a later report.

Inspection of the cognitive test results in Table II shows that in no case where $\bar{D}_{e}-\bar{D}_{c}$ (i.e. the estimate of $\mathrm{G}-\mathrm{P}$ ) is positive, is it significant. In fact, $t$ was found to be less than unity in every such case. For the static ataxia and body sway tests a negative value of G-P was predicted, since improvement in personality would be expected to be associated with decreased sway under the conditions of these tests. Negative values of $\bar{D}_{e}-\bar{D}_{c}$ occur seven times in Table II, and of these seven negative values, one is significant at the 5\% level and one at the $1 \%$ level, by the one-tail $t$-test. In four of the remaining five cases, $t$ was less than unity.

Table III shows the results obtained from the analysis of the scores made by members of the normal senior group on the ten tests which constitute the Wechsler scale I, the five tests of which the P.M.A. group test is comprised, and the static ataxia and body sway tests. Of the three values for $\bar{D}_{e}-D_{c}$ provided by the latter, only one is negative as predicted, and it is not significant. Twenty estimates of G-P are provided by the Wechsler results, and of these 20 , one is significant at the $5 \%$ level, three at the $2 \frac{1}{2} \%$ level, and one at the $1 \%$ level. In only one other case was $t$ greater than unity. By chance alone, one result out of 20 would be expected to be significant at the $5 \%$ level.

TABLE II

\begin{tabular}{|c|c|c|c|c|c|c|c|c|c|c|c|c|c|}
\hline \multirow{2}{*}{ Group } & \multirow{2}{*}{ Statistic } & \multicolumn{2}{|c|}{$\begin{array}{c}\text { Binet Mental } \\
\text { Age } \\
\text { (Months) }\end{array}$} & \multicolumn{2}{|c|}{$\begin{array}{l}\text { Kohs' Blocks } \\
\text { (Raw Scores) }\end{array}$} & \multicolumn{2}{|c|}{$\begin{array}{c}\text { Object } \\
\text { Assembly } \\
\text { (Raw Scores) }\end{array}$} & \multicolumn{2}{|c|}{$\begin{array}{c}\text { Picture } \\
\text { Completion } \\
\text { (Raw Scores) }\end{array}$} & \multicolumn{2}{|c|}{$\begin{array}{l}\text { Static Ataxia } \\
\text { (Half-inches) }\end{array}$} & \multicolumn{2}{|c|}{$\begin{array}{c}\text { Body Sway } \\
\text { (Half-inches) }\end{array}$} \\
\hline & & $\mathbf{E}$ & C & $\mathbf{E}$ & C & $\mathbf{E}$ & C & $\mathbf{E}$ & C & $\mathrm{E}$ & C & $\mathbf{E}$ & C \\
\hline \multirow{2}{*}{$\begin{array}{l}\text { Defective } \\
\text { Adults } \\
\text { Group I }\end{array}$} & $\begin{array}{l}\text { First Period : } \\
\text { Number } \\
\text { Mean Gain }(\dot{\bar{D}} ; \\
\text { Variance } \\
\text { Significance } \\
\cdots\end{array}$ & $\begin{array}{c}14 \\
9 \cdot 21 \\
75 \cdot 26\end{array}$ & $\begin{array}{c}12 \\
14 \cdot 83 \\
63 \cdot 61\end{array}$ & $\begin{array}{l}14 \\
2 \cdot 71 \\
1 \cdot 91\end{array}$ & $\begin{array}{c}12 \\
3 \cdot 00 \\
26 \cdot 36\end{array}$ & $\begin{array}{c}14 \\
1.00 \\
19 \cdot 38\end{array}$ & $\begin{array}{c}12 \\
1.92 \\
26.99\end{array}$ & $\begin{array}{c}14 \\
1 \cdot 36 \\
14 \cdot 71\end{array}$ & $\begin{array}{c}12 \\
1 \cdot 75 \\
8 \cdot 02\end{array}$ & \multicolumn{2}{|c|}{ 一 } & $\begin{array}{c}12 \\
-0.33 \\
2.24\end{array}$ & $\begin{array}{c}12 \\
-0.08 \\
16.45\end{array}$ \\
\hline & $\begin{array}{l}\text { Second Period : } \\
\text { Number } \\
\text { Mean Gain }(\dot{\overline{\mathrm{D}}}) \\
\text { Variance } \\
\text { Significance } \\
\end{array}$ & $\begin{array}{c}10 \\
-4 \cdot 20 \\
52 \cdot 18\end{array}$ & $\begin{array}{c}13 \\
0 \cdot 69 \\
39 \cdot 90\end{array}$ & $\begin{array}{l}10 \\
0 \cdot 60 \\
6.93\end{array}$ & $\begin{array}{l}13 \\
0 \cdot 85 \\
9 \cdot 81\end{array}$ & $\begin{array}{l}10 \\
0 \cdot 00 \\
14 \cdot 00\end{array}$ & $\begin{array}{l}13 \\
1 \cdot 31 \\
8 \cdot 90\end{array}$ & $\begin{array}{l}10 \\
1 \cdot 40 \\
4 \cdot 93\end{array}$ & $\begin{array}{c}13 \\
1 \cdot 38 \\
10 \cdot 09\end{array}$ & $\begin{array}{l}10 \\
0 \cdot 40 \\
3 \cdot 38\end{array}$ & $\begin{array}{c}13 \\
-0.23 \\
1.69\end{array}$ & $\begin{array}{r}8 \\
-1 \cdot 12 \\
2 \cdot 70 \\
\end{array}$ & $\begin{array}{ll} & 13 \\
& 0.85 \\
& 1.97 \\
& \\
\end{array}$ \\
\hline $\begin{array}{c}\text { Defective } \\
\text { Adults } \\
\text { Group II }\end{array}$ & $\begin{array}{l}\text { Only Period : } \\
\text { Number } \\
\text { Mean Gain }(\dot{\overline{\mathrm{D}}}) \\
\text { Variance } \\
\text { Significance } \\
\end{array}$ & $\begin{array}{r}6 \\
3 \cdot 33 \\
98 \cdot 67\end{array}$ & $\begin{array}{c}6 \\
-1 \cdot 17 \\
125 \cdot 77\end{array}$ & $\begin{array}{l}5 \\
1.60 \\
0.80\end{array}$ & $\begin{array}{r}6 \\
2 \cdot 33 \\
16 \cdot 27\end{array}$ & $\begin{array}{c}6 \\
1 \cdot 83 \\
10 \cdot 57\end{array}$ & $\begin{array}{r}\quad 6 \\
2 \cdot 00 \\
11 \cdot 20\end{array}$ & $\begin{array}{c}6 \\
1 \cdot 67 \\
14 \cdot 67\end{array}$ & $\begin{array}{c}6 \\
2 \cdot 50 \\
4 \cdot 70\end{array}$ & $\begin{array}{r}6 \\
-0.33 \\
3.47 \\
\end{array}$ & $\begin{array}{c}\quad 4 \\
2 \cdot 75 \\
2 \cdot 92 \\
\end{array}$ & $\begin{array}{c}6 \\
-0.54 \\
16.57\end{array}$ & $\begin{array}{l}4 \\
0 \cdot 50 \\
0 \cdot 33\end{array}$ \\
\hline \multirow{2}{*}{$\begin{array}{l}\text { Defective } \\
\text { Children }\end{array}$} & $\begin{array}{l}\text { First Period : } \\
\text { Number } \\
\text { Mean Gain }(\dot{\bar{D}}) \\
\text { Variance } \\
\text { Significance }\end{array}$ & $\begin{array}{l}8 \\
1 \cdot 25 \\
4 \cdot 50\end{array}$ & $\begin{array}{r}8 \\
3 \cdot 37 \\
21 \cdot 98\end{array}$ & $\begin{array}{l}8 \\
1 \cdot 50 \\
5 \cdot 43\end{array}$ & $\begin{array}{c}8 \\
1 \cdot 25 \\
3 \cdot 36\end{array}$ & $\begin{array}{l}8 \\
0 \cdot 25 \\
3 \cdot 14 \\
\end{array}$ & $\begin{array}{c}8 \\
-0 \cdot 25 \\
14 \cdot 86\end{array}$ & $\begin{array}{c}8 \\
2 \cdot 25 \\
21 \cdot 93\end{array}$ & $\begin{array}{c}8 \\
3.00 \\
12 \cdot 86\end{array}$ & & & $\begin{array}{c}8 \\
1 \cdot 75 \\
11 \cdot 07\end{array}$ & $\begin{array}{c}7 \\
2 \cdot 14 \\
4 \cdot 48\end{array}$ \\
\hline & $\begin{array}{l}\text { Second Period : } \\
\text { Number } \\
\text { Mean Gain }\left(\dot{\bar{D}}^{\mathrm{i}}\right) \\
\text { Variance } \\
\text { Significance ... }\end{array}$ & $\begin{array}{c}8 \\
1.75 \\
4.96\end{array}$ & $\begin{array}{c}8 \\
0 \cdot 25 \\
11.64\end{array}$ & $\begin{array}{c}8 \\
-0.50 \\
2.75\end{array}$ & $\begin{array}{c}8 \\
0 \cdot 25 \\
3 \cdot 44\end{array}$ & $\begin{array}{c}8 \\
3 \cdot 37 \\
18 \cdot 55\end{array}$ & $\begin{array}{r}8 \\
1 \cdot 50 \\
15 \cdot 71\end{array}$ & $\begin{array}{c}8 \\
0.87 \\
26.41\end{array}$ & $\begin{array}{c}8 \\
1.62 \\
4 \cdot 84\end{array}$ & $\begin{array}{l}7 \\
0 \cdot 14 \\
1 \cdot 48\end{array}$ & $\begin{array}{r}8 \\
-1.00 \\
2.86\end{array}$ & $\begin{array}{r}7 \\
-0.86 \\
5.81\end{array}$ & $\begin{array}{c}8 \\
-1 \cdot 75 \\
14 \cdot 50\end{array}$ \\
\hline \multirow{2}{*}{$\begin{array}{c}\text { Normal } \\
\text { Boys } \\
\text { Junior } \\
\text { Group }\end{array}$} & $\begin{array}{l}\text { First Period : } \\
\text { Number } \\
\text { Mean Gain }(\dot{\bar{D}}) \\
\text { Variance } \\
\text { Significance } \ldots\end{array}$ & $\begin{array}{c}12 \\
3.83 \\
93.61\end{array}$ & $\begin{array}{r}12 \\
2 \cdot 50 \\
101 \cdot 36\end{array}$ & $\begin{array}{l}12 \\
1 \cdot 75 \\
0 \cdot 75\end{array}$ & $\begin{array}{c}12 \\
1.67 \\
1.33\end{array}$ & $\begin{array}{c}12 \\
1 \cdot 58 \\
10 \cdot 81\end{array}$ & $\begin{array}{c}12 \\
0 \cdot 67 \\
4 \cdot 24\end{array}$ & $\begin{array}{c}12 \\
1.67 \\
13 \cdot 33\end{array}$ & $\begin{array}{c}12 \\
1.42 \\
19.90\end{array}$ & \multicolumn{2}{|c|}{-} & $\begin{array}{r}12 \\
-1 \cdot 25 \\
4 \cdot 85\end{array}$ & $\begin{array}{r}11 \\
-1.00 \\
15.09\end{array}$ \\
\hline & $\begin{array}{l}\text { Second Period : } \\
\text { Number } \\
\text { Mean Gain }(\dot{\overline{\mathbf{D}}}) \\
\text { Variance } \\
\text { Significance } \\
. .\end{array}$ & $\begin{array}{c}11 \\
5.45 \\
102 \cdot 47\end{array}$ & $\begin{array}{c}10 \\
5 \cdot 10 \\
21 \cdot 88\end{array}$ & $\begin{array}{l}11 \\
0 \cdot 36 \\
4 \cdot 65\end{array}$ & $\begin{array}{c}10 \\
1 \cdot 20 \\
6 \cdot 18\end{array}$ & $\begin{array}{l}11 \\
1.64 \\
17.65\end{array}$ & $\begin{array}{c}10 \\
0 \cdot 00 \\
17 \cdot 78\end{array}$ & $\begin{array}{l}11 \\
2 \cdot 64 \\
8 \cdot 25\end{array}$ & $\begin{array}{l}10 \\
3 \cdot 20 \\
7 \cdot 73\end{array}$ & $\begin{array}{c}10 \\
-0 \cdot 20 \\
7 \cdot 73\end{array}$ & $\begin{array}{r}10 \\
-0.30 \\
8.46\end{array}$ & $\begin{array}{l}10 \\
0 \cdot 50 \\
0 \cdot 94\end{array}$ & $\begin{array}{l}10 \\
0 \cdot 60 \\
3 \cdot 38\end{array}$ \\
\hline
\end{tabular}


TABLE III

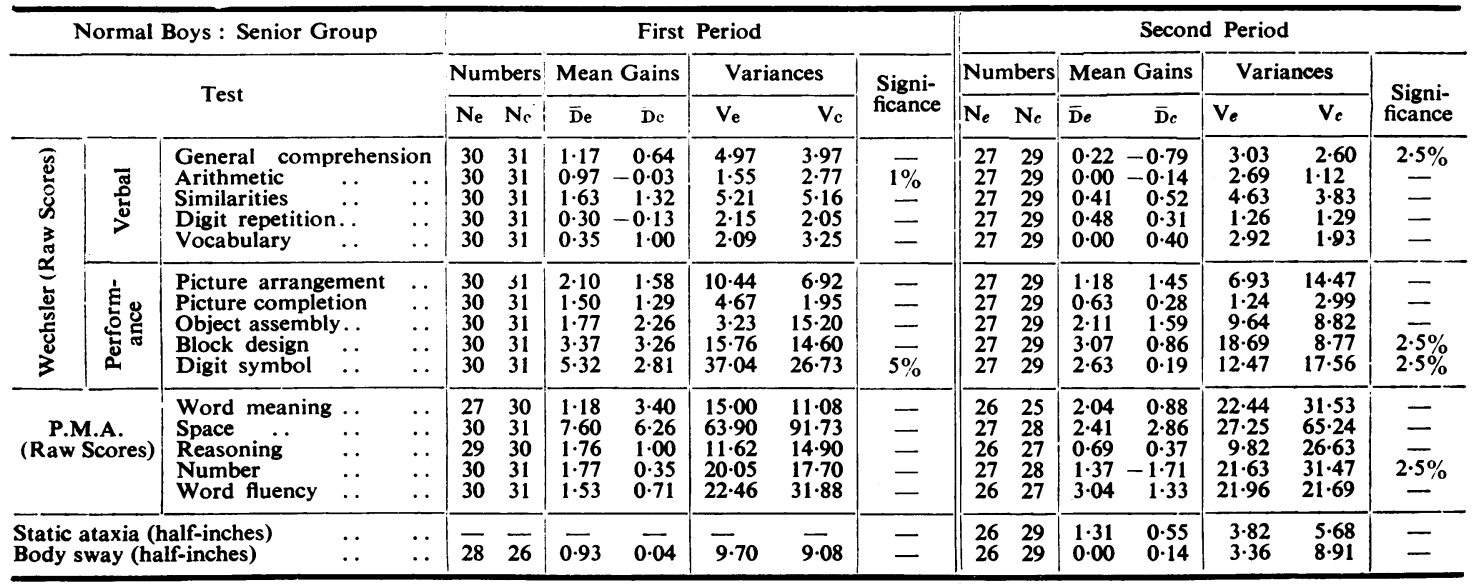

Of the ten estimates of G-P derived from the P.M.A. scores, one is significant at the $2 \frac{1}{2} \%$ level. By chance, one out of ten would be expected to be significant at the $10 \%$ level. Values of $t$ greater than unity were found in two other cases in the P.M.A. results.

It will be observed that, whereas in Table II 16 of the 28 values for $\bar{D}_{e}-\bar{D}_{c}$ derived from the cognitive test scores are negative, Table III shows only seven out of 30 values for the same function to be negative.

\section{Discussion}

It seems fairly clear that the cognitive test results in Table II (i.e. those of the three defective groups and the junior normal group) afford no evidence whatever in favour of the hypothesis. Not only is none of the positive differences significant, but there are approximately as many negative as positive differences, which is in accord with chance expectation.

The results of the ataxia and suggestibility tests are more difficult to interpret. There are 14 such results altogether, including those in Table III, as the tests were exactly the same for the senior normal group. Eight of these, that is, just over half of them, are in the predicted direction, which, again, is in accordance with chance expectation ; but two of them are significant, one at the $1 \%$ level, and one at the 5\% level. Strictly speaking, this is not what would be expected on a chance hypothesis, but the departure from a chance prediction is scarcely large enough to be regarded as affording any but the slenderest evidence in favour of the hypothesis of personality improvement.

The results obtained from the Wechsler scores of the senior normal group (Table III) show some departure from the general pattern of the other results. These scores provide 20 estimates of G-P or, more precisely, ten of G-P and ten of 2(G-P) : the distinction is immaterial in the present context. Fifteen of these estimates are in the predicted direction, and five of them are significant. On a chance hypothesis, ten would be expected to be positive, and one to be significant at the $5 \%$ level. It does appear, therefore, that in this case there is some slight evidence in favour of the main hypothesis. A difficulty arises, however, from the fact that the tests used are not independent. The tests which yielded the significant differences are the digit symbol $\left(5 \%\right.$ and $\left.2 \frac{1}{2} \%\right)$, block design $\left(2 \frac{1}{2} \%\right)$, general comprehension $\left(2 \frac{1}{2} \%\right)$, and arithmetic $(1 \%)$. Examination of the table of inter-test correlations given by Wechsler (1944), based on 355 cases in the 20-34 age group, discloses that the inter-test correlations under consideration range from 0.429 to 0.538 The table shows eight inter-correlations higher than 0.538 and 17 lower than 0.429 . The highest in the table is 0.721 , the median is 0.456 , and the lowest is $0 \cdot 155$. If these published (American) inter-correlations are accepted as a basis for comparison in the present case, the objection that the tests are not independent appears to have force.

An alternative approach is to consider the character of the tests which have yielded significant results. In all except one (general comprehension) the score of the subject depends partly on his speed of performance. This suggests that the observed effect of glutamic acid on the test scores may be explicable in terms of a general improvement in mental and physical alertness, or of a raising of the general activity level, as reported by other investigators. If this were so, then significant differences would be expected in the P.M.A. scores, since the 
five tests in this battery are all rigorously timed. Table III shows that eight of the ten estimates of G-P [or 2(G-P)] derived from these scores are in the predicted direction, and one of them is significant at the $2 \frac{1}{2} \%$ level. Although this is slightly above chance expectation, it is less so than in the case of the Wechsler scores. It is unlikely, therefore that improvement in alertness, activity, or speed because of glutamic acid accounts for the improvement in the Wechsler scores. *

The general conclusion must be that the changes in the test scores of the subjects who were fed with glutamic acid in this experiment have provided little or no evidence in favour of the hypotheses which were to be tested.

The glutamic acid was administered in this experiment as a solution, neutralized with caustic soda : the New York investigators administered it suspended in water. As there is a possibility that the effects of these two modes of administration might be different because of the large amount of alkali received in the former, a subsidiary experiment was carried out by Dr. D. L. Davies. Since it was not practicable to determine the glutamate level in the blood at regular intervals after ingestion, because of the large quantity of blood required for each estimation and the uncertainty as to the range of individual variation, it was decided to measure the total acidity of the urine, and the serum alkali reserve after glutamic acid and after sodium glutamate, in order to test the correctness of an assumption that on an ordinary mixed diet no difference in the effect upon alkali reserve would be found. Two patients were studied. Patient A, aged 27, was observed over a period of five weeks in hospital. His diet was the ordinary hospital fare. During the first week he received no drugs. During the second week he received $10 \mathrm{~g}$. of sodium glutamate b.d. for the first five days; on the sixth day the morning dose was doubled and on the seventh day both doses were doubled. During the third week no drugs were administered. During the fourth week he received $10 \mathrm{~g}$. of glutamic acid powder for the first five days; on the sixth day the morning dose was doubled and on the seventh day both doses were doubled. During the fifth week no drugs were administered. Throughout this period 24 hour specimens of urine were collected, checked by the estimation of total creatinine, and

\footnotetext{
* A small experiment, designed similarly to that described in this paper, was conducted by Dr. B. H. Kirman and Miss S. M. Cox at the Fountain Hospital, Tooting. The subjects were three pairs of children, with I.Q.s ranging from 36 to 58 (Stanford-Binet), and the test battery consisted of a variety of standard verbal and performance tests. The period of administration was three months, which was repeated with the subjects in reversed roles. No significant evidence of improvement due to glutamic acid was obtained, but the biggest increases observed in the experimental subjects were those in the Porteous maze test.
}

F* subjected to titration of total acidity by Folin's method, the results being expressed in $\mathrm{ml} . \frac{\mathrm{N}}{10}$ alkali. Every Monday, Wednesday, and Friday morning at 11 a.m., with the patient resting in bed for at least 30 minutes, venous blood was taken for the estimation of serum alkali reserve by Van Slyke's titration method, the result being expressed in vols. of $\mathrm{CO}_{2} / 100 \mathrm{ml}$. Patient $\mathrm{B}$, a man aged 39, suffering from a chronic anxiety state, was subject to the same procedures except that he received glutamic acid on the days when Patient $\mathrm{A}$ received sodium glutamate, and vice versa. This was to remove any subjective bias in the technical assistants who did not know which drug the patients were receiving. In neither patient was there evidence of impairment of kidney or liver function. No symptoms suggestive of acidosis or alkalosis were observed. The results are shown in Table IV on page 54.

Although the expected shifts in the total titratable acidity of the urine occurred, the fluctuations in the alkali reserve followed no such clear-cut trend. Indeed the lowest reading in Subject A was obtained in the initial control period after he had recently finished strenuous physical exercise. The changes in the level of the alkali reserve were evidently well within the normal physiological range. Any difference between the effects obtained after glutamic acid and those obtained after sodium glutamate cannot be attributed to different effects upon the alkalinity of the serum.

\section{Summary}

Two groups of mentally defective adults, one group of mentally defective children, and two groups of normal boys, were divided each into an experimental and a control section. Before and after treatment with glutamic acid or with an indifferent substance, each subject was given verbal, performance, and personality tests. After the second test administration each subject was transferred to the opposite section for a further period of treatment, at the end of which the tests were administered for a third time. The results of the cognitive tests provided no evidence in favour of the hypothesis that glutamic acid improves cognitive functioning, except in one group of normal boys, whose findings yielded slight but equivocal evidence in favour of the hypothesis. For the additional hypothesis, that scores on the personality tests would be improved, there was no evidence.

We wish to record our indebtedness to Dr. H. E. Magee, of the Ministry of Health, for advice regarding the choice of a home for normal children, and to Dr. Gilmore and the authorities of Dr. Barnardo's Homes for permission to conduct part of the trial in New Lodge, Windsor; to the Superintendent, Mr. Mace, and to Mrs. Mace and the staff of the New Lodge, Windsor, to 
TABLE IV

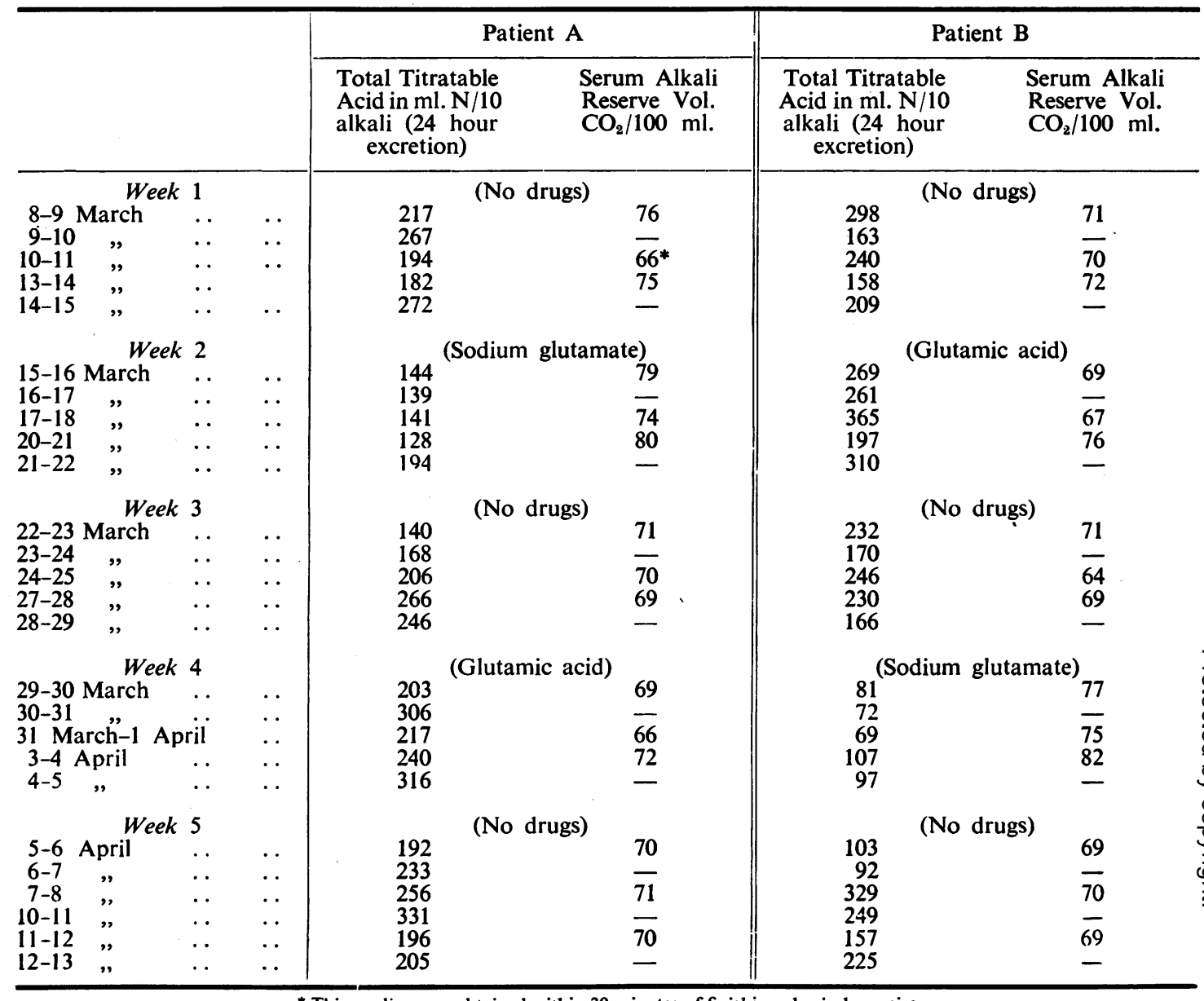

* This reading was obtained within 30 minutes of finishing physical exercise.

Dr. H. T. McMahon and the pharmacist and other members of staff of the Manor Hospital, Epsom, and to Dr. L. T. Hilliard and the pharmacist and other staff of the Fountain Hospital, for their willing cooperation ; and to $\mathrm{Mr}$. A. Lubin for his guidance in the statistical analysis. The Ministry of Health, by arrangement with Professor Aubrey Lewis, provided the glutamic acid and defrayed part of the expenses.

\section{REFERENCES}

Albert, K., Hoch, P., and Waelsch, H. (1946). J. nerv. ment. Dis., 104, 263.

Albert, K. E., and Warden, C. J. (1944). Science, 100, 476.

Ewalt, J. R., and Bruce, E. I. (1948). Tex. Rep. Biol. Med., 6, 97.

Eysenck, H. J. (1947). “ "Dimensions of Personality.” London.

Fisher, R. A. (1941). " "Statistical Methods for Research Workers", 8th ed. Edinburgh.

Gasorek, K.A. (1948). Amer. Psychologist, 3, 253.

Hamilton, H. C., and Maher, E. B. (1947). J. comp. physiol. Psychol., 40, 463.
Harney, M. (1950). Stud. Psychol. Psychiat. Cathol. Univ. Amer., 8, 1.

Kitzinger, H., DeVere, G. A., Cartwright, R. W., and Shapiro, D. (1949). Rorschach Res. Exch. J. Proj. Tech., 13, 210.

Marx, M. H. (1948). J. comp. physiol. Psychol., 41, 82.

Price, J., Waelsch, H., and Putnam, T. (1943). J. Amer. med. Ass., 122, 1153.

Stellar, E., and McElroy, W. D. (1948). Science, 108, 281.

Waelsch, H., and Price, J. (1944). Arch. Neurol. Psychiat., Chicago, 51, 393.

Wechsler, D. (1944). "The Measurement of Adult Intelligence ", 3rd ed. Baltimore.

Zimmerman, F. T., Burgemeister, B. B., and Putnam, T. J. (1946). Arch. Neurol. Psychiat., Chicago, 56, 489. Zimmerman, F. T., Burgemeister, B. B., and Putnam, T. J., (1947). Psychosom. Med., 9, 175.

$\longrightarrow,-$, , (1948). Amer. J. Psychiat., 104, 593.

Chicago, 61, 275.

- and Ross, S. (1944). Arch. Neurol. Psychiat., Chicago, 51, 446. 